\title{
Beliefs and attitudes about assessment of a sample of student teachers in South Africa
}

\author{
Saloshna Vandeyar \\ Roy Killen
}

\begin{abstract}
The purpose of this study was to take the first steps in a long-term approach to helping South African teachers understand and respond to government demands that they change their assessment practices. Specifically, it attempted to identify the beliefs, perceptions and attitudes about assessment that student teachers bring with them to courses that are designed to equip them to teach in ways that are consistent with current curriculum trends in South Africa. The study attempted to answer the following research questions: are student teachers' beliefs about assessment consistent with the approaches to assessment advocated in the South African Revised National Curriculum Statement? Are student teachers' beliefs about assessment consistent with the basic principles of outcomes-based education? The results indicated broad general agreement between student teachers' beliefs about assessment and the principles of assessment espoused in the Revised National Curriculum Statement. However, there was evidence that the beliefs of some of the subjects were inconsistent with these principles.
\end{abstract}

Key words: assessment; attitudes; beliefs; curriculum; educational policy; student teachers

\section{Introduction and background to study}

When outcomes-based education was introduced into the South African education system, teachers were encouraged to make a paradigm shift - to question their assumptions and to adopt new ways of thinking about teaching and learning (Fleisch 2002; Kraak and Young 2001). The ultimate success of the proposed changes relies, quite specifically, on the way teachers respond to these calls for change because as Delandshere $(1999,214)$ points out, only teachers' 'understanding and transformation of reform proposals into teaching action can change educational practice'. These calls for change are causing concern for many teachers; in some cases because they do not understand what they were being asked to do and in other cases because the suggested changes challenged their beliefs. These challenges are particularly evident in relation to assessment. For example, the National Assessment Policy in the General Education and Training Band Grade R to 9 and Adult Basic Education and Training (ABET) encourages teachers to use continuous assessment rather than just end-of-year examinations (a well-established tradition in school education in South Africa).

The broad educational reforms that have been mandated in South Africa over the past ten years are an attempt to redress the inequalities of the past and, broadly speaking, are based on the principles of outcomes-based education (OBE). Official statements such 
as 'assessment in Grades 10-12 (schools) adheres to the principles of outcomes-based assessment' (Department of Education 2002a, 27) and 'the Revised National Curriculum Statement ... affirms the commitment to outcomes-based education' (Department of Education 2002b, 6) clearly indicate that teachers are being encouraged to adopt new assessment practices that are perceived by the South African government and by the Department of Education as being consistent with the principles of OBE.

Although the broad thrust of these reforms has been criticised by many commentators (see, for example, Jansen 1999) there are widely held views that the recommended changes to assessment practices in schools are appropriate and should be supported (see, for example, Fraser and Maree 2004). Quite clearly, the success of these proposed reforms rests heavily on teachers' understanding of OBE.

Prior to the introduction of Curriculum 2005 (the official title of the revised school curriculum introduced in 1998), assessment in most South African schools was a rather straightforward process of testing students' ability to reproduce information that was presented to them through a content-based curriculum. In the early years of the change to an outcomes-based curriculum, teachers were required to use forms of criterion-referenced assessment that would enable them to 'tick off' the outcomes that students had achieved. Before most teachers have begun to feel comfortable with this change, they are being asked to change again - to a standards-referenced approach that will require them to distinguish between different levels of achievement by making qualitative decisions using frames of reference that are alien to many South African teachers (Department of Education 2002b; Killen 2000).

The new directions for assessment in South African schools are described in detail in the Draft National Curriculum Statement for Grades 10-12 (Department of Education 2002a) and the Revised National Curriculum Statement for Grades R-9 (Department of Education 2002b). The latter document emphasises a shift from the criterion-referenced assessment that was recommended in Curriculum 2005 to a form of standards-referenced assessment based on a set of outcomes that define what learners are expected to achieve in each Learning Area in each phase of schooling. For each grade (year) of schooling within each phase, there is a set of assessment standards that defines the levels of knowledge, skills and attitudes that learners will be required to demonstrate as evidence that they have achieved each phase outcome to an appropriate depth and breadth. These grade-specific standards describe how learners' conceptual understanding and skills are meant to progress in each Learning Area. This concept of focusing assessment on pre-defined standards is a significant departure from the content-focused approach to assessment that was common in the past in South African schools.

As Vandeyar and Killen $(2003,131)$ point out, the introduction of standards referencing has important implications for teaching and assessment. For the first time in South Africa, teachers are being encouraged to think of attainment of each outcome as a continuum of possibilities, rather than as a dichotomy. They are no longer being asked 
to put learners into categories of 'achieved/not achieved' for each outcome. Instead they have to think about how well each learner has achieved each outcome. This is a rather dramatic change from the way teachers approached assessment just a few years ago.

These suggested changes could be viewed in two ways. On the one hand, they can be seen as a reaction to some of the inappropriate and inequitable practices of South Africa's previous education system. On the other hand, they can be seen as a proactive reflection of more than a decade of international trends towards alternative forms of assessment (Resnick and Resnick 1992; Herman, Aschbacher and Winters 1992). These international trends have seen a shift in emphasis from testing the mastery of isolated and often decontextualised facts, to testing integrated meaning-making in authentic contexts. This so-called authentic assessment requires students to answer important questions, solve real or realistic problems, and engage in non-routine and multistage tasks that require high-quality performance (Wiggins 1993; Montgomery 2001). Authentic assessment practices, such as those suggested by Wiggins, often include investigations conducted collaboratively, hands-on solving of real problems, performances completed over extended periods of time and the presentation of evidence of learning through portfolios or non-written products. Authentic assessment is designed to make assessment an integral part of learning.

This shift in the focus of assessment reflects shifts in views about learning. When learning is viewed as the mastery of discrete decontextualised knowledge and skills, it is logical to measure achievement of that learning through formal, teacher-directed standardised tests that enable deficits in learning to be identified and learners to be ranked. This norm referencing allows underachievement (relative to the norm) to be identified and attributed to individual learners. Alternatively, when learning is viewed as the personal construction of meaning it becomes necessary to take a more holistic and integrated view of assessment. Assessment becomes 'more of an informal, longterm monitoring process that provides an indication of student competence on various types of authentic activities and is used to guide instruction' (Rueda and Garcia 1994, 4). Assessment tasks become developmental tools rather than just measurement tools. Whether or not these different approaches to assessment are couched in terms of OBE (as they are in South Africa) they are not simply changes in instructional practices, they represent (and require) changes in teachers' underlying beliefs, which, in turn, depend upon changes in teachers' theoretical knowledge base.

Herein lies a major challenge in curriculum reform. There is considerable evidence to suggest that teachers' instructional practices, including their approaches to assessment, are guided by their beliefs about learners and learning (Clark and Peterson 1986; Delandshere 1999; Jansen 2001; Jita 2002; Meier and Lemmer 2001). These beliefs regarding the nature and function of learning and the role of instructional practices such as assessment 'can be seen as integrated systems of concepts, scripts, and scenes which function to lend meaning to the action systems of classrooms' (Rueda and Garcia 1994, 1). In general, teachers' 'implicit theories and beliefs about assessment inform their 
thinking and planning and, consequently, shape their classroom assessment practices' (Bliem and Davinroy 1997, 3). However, teachers' beliefs about specific instructional practices, such as assessment, are not decontextualised; they are situation-specific. This is one of the reasons why teachers' beliefs are so difficult to change: their beliefs lend meaning to their actions by influencing perceptions and judgements so teachers' natural tendency is to act in ways that reinforce those beliefs. It seems unlikely that the beliefs about assessment held by South African teachers will be any less resistant to change than the beliefs of teachers in the studies referred to above. In fact, the general resistance to the introduction of OBE in South Africa (Jansen 1999; Department of Education 2000 ) is probably an indication that the resistance to changing assessment practices will be quite strong.

Of course, teachers should not be expected to accept the new assessment policies uncritically. Nor should teacher educators merely indoctrinate students with the rhetoric of current policy discourse. Teachers, and student teachers, should be encouraged to examine these new policies from an informed position. It is the view of the authors that such an examination will reveal two important factors: first, that the proposed changes are broadly aligned with contemporary views on effective assessment; second, that it will be difficult for teachers to understand the proposed changes (and rationally accept or reject them) unless they have a sound understanding of the principles of OBE. This latter point is particularly important because the changes are proposed within a framework of OBE and, as Killen (2002) argues, it is illogical to accept or reject any aspect of OBE without first attempting to understand it.

It must be acknowledged that some South African teachers are already using assessment practices that provide reliable evidence from which valid inferences can be drawn about their students' learning. However, there is strong evidence to suggest that this is the exception rather than the rule (Fraser and Maree 2004), particularly in 'formerly disadvantaged' schools (Vandeyar and Killen 2003). If the assessment practices in South African schools are to change in any consistent way (not simply the way being currently suggested), a two-pronged approach will be needed. Experienced teachers will have to be convinced that they can and should change their practices and new teachers will have to be educated in the new approaches. It is not easy to change the assessment practices of experienced teachers (Hunsaker and Johnston 1992; Bliem and Davinroy 1997; Johnston et al. 1995; Jansen 1999; Potenza and Monyokolo 1999). Nor is it easy to encourage student teachers to use practices that are different from those that they experienced as learners (Brookhart and Freeman 1992; Richards and Killen 1996). However, in the case of South Africa it is essential to lay the foundations for these changes in teacher education programmes because of the relative ineffectiveness of many recent attempts at in-service teacher education (Mkhabela 1999; GICD 2000; Malcolm 2000). 


\section{Purpose and research questions}

The purpose of this study was to identify the beliefs, perceptions and attitudes about assessment that a small sample of student teachers brought with them to courses that are designed to equip them to teach in ways that are consistent with current curriculum trends in South Africa. The study attempted to answer the following research questions: are student teachers' beliefs about assessment consistent with the approaches to assessment advocated in the Revised National Curriculum Statement? Are student teachers' beliefs about assessment consistent with the basic principles of OBE? No attempt was made to resolve the contentious issue of whether or not the mandated reforms (including the general OBE framework) are appropriate. The authors acknowledge that OBE and the proposed assessment reforms have limitations and that they should not be accepted uncritically. However, this study was based on the premise that if student teachers' beliefs about OBE and assessment can be made explicit, then the potential validity of those beliefs can be tested and the beliefs can be used as a basis for critiquing both current and future policy reforms. The current study is simply a first step in the long-term process of empowering teachers to critique the policies they are expected to implement.

\section{Subjects}

The subjects of this study were 48 student teachers who had enrolled in a one-year Postgraduate Certificate in Education (PGCE) programme at a large South African university in 2004. This programme is designed for prospective secondary school teachers. These student teachers were predominantly white and Afrikaans-speaking. Of these student teachers, 44 were females and four were males. Of these student teachers 37 had completed an undergraduate degree in one or more fields of specialisation, and 43 of these student teachers had no undergraduate courses in education. They came from a variety of academic and professional backgrounds, having completed undergraduate degrees in areas as diverse as Arts, Science, Commerce, Journalism and Psychology. The gender, race and academic background of these student teachers was typical of student teachers who enrol in the PGCE programme at the university where the study was conducted. There is no claim that this sample is representative of the population of student teachers in South Africa at the time of the study.

All student teachers in the study completed their schooling prior to the recent change to an OBE system. Their undergraduate degrees were also completed prior to the introduction of OBE at universities. Since their knowledge of assessment practices was generally limited to the assessment practices to which they have been exposed as students (at school and university) it was reasonable to assume that the information they provided to the researchers would be based on their underlying beliefs rather than on any conception of what they thought they should be saying about outcomes-based assessment. This was the prime reason for gathering the data before these student teachers had received any instruction on assessment in their teacher education programme. 


\section{Methodology}

To answer the research questions, it was necessary to identify the features of assessment that are advocated in the Revised National Curriculum Statement and to identify the extent to which these approaches to assessment are consistent with the principles of OBE (using sources such as Spady 1994 and Killen 2000). Theoretically, the assessment principles embedded in the Revised National Curriculum Statement should be consistent with the principles of OBE, but this could not be assumed to be the case. Analysis of the Revised National Curriculum Statement and documents describing outcomes-based assessment yielded a list of statements such as 'the real definition of student achievement is how well students can do things after they have had extended opportunity to practice and improve' (Spady 1994, 53), 'assessment must be closely linked to the outcomes you want learners to achieve' (Killen 2000, 24) and 'assessment must be an on-going, integral part of the learning process' (Department of Education 2002a, 27). These statements were used to construct a questionnaire consisting of 32 items to measure beliefs about assessment. Respondents used a five-point Likert-type scale ( 1 = strongly disagree, $5=$ strongly agree) to indicate to what extent they agreed with each statement.

The items on the questionnaire related to the following key principles of outcomesbased assessment (Spady, 1994): clarity of focus (items 8, 14, 18, 22, 24 and 32), high expectations for learner success (items 7, 15, 17 and 27), providing expanded learning opportunities (items 1, 5, 6, 9, 13, 16, 20, 25, 28, 29 and 30), designing down (items 11 and 12) and aligning outcomes, teaching and assessment (items 2, 3, 4, 10, 19, 21 , 23, 26 and 31). In addition, there were six free-response questions: three relating to the fundamental principles of assessment, one related to portfolio assessment, one related to outcomes-based education and one related to differences between OBE assessment and traditional assessment. The questionnaire was administered on the first day that the student teachers attended the PGCE module on assessment, prior to receiving any instruction on assessment.

Ideally, any exploration of teachers' beliefs should not rely exclusively on paperandpencil tasks, but should also examine how their (possibly unrecognised) beliefs influence their behaviours in authentic situations. In the present study this was not possible because the subjects were not engaged in teaching.

\section{Results and Discussion}

The results from the quantitative section of the questionnaire are summarised in Table 1 (at end of the article), with the items rearranged into the five groups described above.

The first group of questions focused broadly on the OBE principle of 'clarity of focus' (Spady 1994, 11), that is, the idea of having a clear picture of the learning that students 
are required to demonstrate and focusing directly on this learning in assessment tasks. By implication, it is the level of achievement of these clearly defined outcomes that should be reported. There was strong agreement with the propositions posed in three of these items - that outcomes should be assessed in real-world contexts, that assessment should enhance learning, and that reporting should emphasise individual progress and growth. These are all factors emphasised in the authentic assessment literature (Wiggins 1993) and in the Revised National Curriculum Statement.

The other three propositions in the first group of questions received weaker (but still positive) support. The fact that not all student teachers supported the idea that 'assessment should measure what is valued in student learning' is of some concern because it implies that some respondents consider it legitimate for assessment to measure things that are not valued. The reason for the average support for the idea that 'assessment results should be reported in ways that best serve the audience' is not obvious. The question may have confused some respondents.

The average response of 3.32 (out of 5) on the item 'marks and letter grades are meaningful ways to report learner achievement' is interesting. Because so many educational institutions in South Africa continue to use these forms of reporting, it is obvious that there is widespread general agreement with this proposition. However, there are arguments from writers such as Spady (1994), Rusin (1999) and Killen (2003) to suggest that there are more meaningful ways to report student achievement than marks or grades. In recent years there have been some quite significant moves away from marks and grades, usually as part of the introduction of standards-referenced assessment (Board of Studies NSW 2002). On this issue, the Revised National Curriculum Statement attempts 'to provide for a gradual transition between current assessment practice and the new OBE assessment' through 'a combination of mark allocation and criterionreferenced descriptors' (Department of Education 2002b, 25). It appears that at least some of the respondents in the current study may be receptive to new ways of reporting student achievement.

The second group of questions focused on Spady's $(1994,16)$ principle of 'high expectations'. This is also a prominent feature of authentic pedagogy (Newmann and Associates 1996), productive pedagogy (Luke et al. 1998) and quality teaching (Department of Education and Training 2003). Having high expectations for all students encourages teachers to emphasise intellectual quality (higher-order thinking rather than memorisation) in assessment tasks. The respondents agree with the propositions that assessment tasks should be challenging and that this would not necessarily lead to high failure rates. They also agreed that teachers should reveal their marking criteria in advance.

The third group of questions focused on Spady's $(1994,12)$ principle of 'expanded opportunity and support for success'. The main implications for assessment embedded in this principle are that learners must be given more than one chance to demonstrate 
their learning and that these opportunities must take account of the characteristics of the learners. The questionnaire item that expressed this principle most directly was 'assessment should provide learners with multiple opportunities to improve the quality of their work' and this item received the lowest rating in this group (3.88). It seems that some respondents held strong beliefs that assessment should be a one-off event. However, there was a high level of agreement on all but one of the other items in this group, suggesting that respondents' views on assessment were generally aligned with the principle of providing expanded opportunities for students to learn, even if they were not explicitly aware of the principle.

There was one item in this group that received low ratings (mean of 2.71) and that was 'assessment tasks should be designed so that most learners in a class do well on most tasks'. This item reflects very directly Spady's (1994:9) premise that 'successful learning promotes even more successful learning'. It also reflects the philosophy that achievement of outcomes should be viewed as a continuum, not a dichotomy (Killen 2004). It is possible that the respondents were taking the view that if most learners do well then the task must be assessing low levels of learning (which could very well have been the case in their past experiences).

The fourth group of questions focused on Spady's (1994:18) principle of 'designing down' from the 'culminating outcomes' that learners are to achieve when their formal learning experiences are complete to the 'enabling outcomes' that they will achieve lesson by lesson. The main implication for assessment embedded in this principle is that learners' achievement of the enabling outcomes must be assessed continuously so that, when necessary, further opportunities for learning can be provided. There was sufficient, although not complete, agreement from respondents with regard to both statements in this group. Respondents may have been confused by the inclusion of the words 'the primary purpose of assessment' in one of the items.

The fifth group of questions focused on the concept of aligning outcomes, teaching and assessment. This idea is referred to by Spady $(1994,11)$ as part of his "clarity of focus' principle but has been separated from it here to emphasise the importance of this alignment. As Anderson and Krathwohl (2001) and Killen (2004) argue, if outcomes, teaching and assessment are not closely aligned the information teachers obtain from assessing learners is unlikely to be of much value. The draft National Curriculum Statement for Grades 10-12 emphasises the importance of alignment by stating that 'the methods and techniques used must be appropriate to the knowledge, skills, or attitudes to be assessed' (Department of Education 2002a, 27). Respondents in the current study seemed to be aware of the need for alignment, with average responses above 4 on seven of the ten items in this group. There was a reasonable level of agreement (mean 3.83) with the idea that 'all aspects of the assessment process should be open to review and scrutiny' which is a factor in high quality assessment practices that is emphasised very strongly by Tognolini (2000) in his writing about standards-referenced assessment. Many respondents seemed to agree with the idea that one method of assessment could 
give 'information about the full range of learning outcomes in a course', possibly because they were accustomed to examinations as the prime method of assessment in their earlier studies. However, there was a low level of agreement (mean 2.44) on the proposition that 'written tests and examinations are usually the best way to check learners' understanding'.

Overall, the results summarised above suggest that the majority of respondents was likely to be receptive to many of the principles of outcomes-based assessment and, therefore, to the general directions of the current departmental assessment policies, because their current beliefs were broadly consistent with these principles.

The responses to the open-ended questions are summarised below.

\section{How would you define 'outcomes-based education'?}

Student teachers who understood the concept of OBE were expected to give an answer similar to: 'Outcomes-based education means clearly focusing and organising everything in an education system around what is essential for all students to be able to do successfully at the end of their learning experiences' (Spady 1994, 1).

A small number of respondents (8\%) had obviously learnt about OBE prior to answering this question and gave responses such as 'OBE aims to prepare learners for life and focuses on developing thinking skills, rather than accumulating facts. It is criterion referenced, rather than norm-referenced. It places emphasis on outcomes and its principles include, clarity of focus, designing down, high expectations and expanded opportunity' (L15).

A further 8 per cent of respondents answered the question in terms of outcomesbased assessment, giving responses such as 'as assessor you must stipulate the outcomes clearly and assess according to those outcomes. It is no longer done according to the old paradigm, where there were tests and exams written. You must continuously assess the learners' tasks and assignments according to the outcomes' (L6).

Approximately 75 per cent of the respondents identified elements of OBE in their responses, with varying degrees of emphasis. About half of these responses suggested that OBE involved the achieving of outcomes and coupled this response with comments about 'tapping the potential of the learner' (L27) or solving of real-life problems or applying knowledge in real-life situation.

The idea that OBE is 'learner-centred' was emphasised in 27 per cent of the responses. For example, 'A learner-centred approach that focuses on the outcome of the learning instead of learning content' (L36). A further 6 per cent emphasised its flexibility, for example, 'It is a system which is more flexible then the old system'. A small number of respondents $(5 \%)$ had the narrow view that 'outcomes-based education facilitates group work' (L28). 
Approximately 8 per cent of the respondents expressed serious misconceptions about OBE, for example, 'Everyone thrown together to do the same tasks, everyone getting the same results thus the stronger learners get pulled down to a mediocre level, and the unsatisfactory learners get pulled along' (L48).

What differences would you expect to see between 'outcomes-based assessment' and the types of assessment you experienced at school?

Student teachers who understood the concept of outcomes-based assessment were expected to mention differences related to the purpose of assessment, the forms of assessment, the timing of assessment and the way in which results were reported.

Approximately 67 per cent of the respondents provided answers that suggested they had some awareness of these differences. However, responses tended to focus on single issues such as continuous assessment, fairness, life-skills or real-life applications, or a move away from norm-referencing assessment. For example, 'No longer question papers and exams, where all the points are calculated in order for the learner to progress to the next grade, but continuous assessment on the grounds of products and how the learner came to this end product. There is much more emphasis on real-life situations and on life-skills' (L41). The remaining 33 per cent of respondents revealed a poor or very limited understanding of outcomes-based assessment, or simply mentioned the deficiencies of the old system and did not contrast these with any features of the new outcomes-based assessment system. For example, 'that the final mark that appears in your report, now is reflected as 1 out of 4/5, no longer with your true symbol (A, B, $\mathrm{C}+\mathrm{D}$ etc). All your tests are stored in a file that the teacher keeps and not just the marks written down in the mark book and the children no longer keep their tests' (L11). 'The learners need to know more about each specialist subject, because during my time we wrote tests to be assessed' (L18).

\section{What do you think is meant by the term 'reliable assessment'?}

Student teachers who understood the concept of reliability in assessment were expected to give an answer similar to: 'A test's reliability refers to the consistency with which it measures whatever it happens to be measuring' (Popham 1990, 54). Approximately 18 per cent of the students gave answers that indicated a basic understanding of this concept, albeit with an emphasis on stability rather than internal consistency (the two components of reliability emphasised by Popham, 1990). They gave answers such as: 'When used repeatedly it will give the same results' (L42) and 'The assessment will measure the same thing over and over again' (L23) and 'If you test a learner a second time the results won't differ from the first time' (L26). In addition, two students mentioned measurement errors (the third component of reliability). For example, 'Reliable assessment is free of measurement errors' (L14). 
A further 22 per cent of these student teachers indicated a partial understanding of the concept by referring to reliable assessment as giving a true reflection of learners' achievements. They gave answers such as: 'Assessment results must be a true reflection of the learner's potential' (L22) and 'Assessment is designed in such a way that the result is a true reflection of the learner's progress' (L36).

Approximately 12 per cent of these student teachers confused reliability with validity and gave answers such as: 'The assessment assessed what it was meant to assess' (L1) and 'It measures what it is supposed to measure' (L16). About 18 per cent of these student teachers just restated the question in terms such as: 'Assessment must be reliable' (L4) and 'Assessment must be done in such a manner so that it can be reliable' (L20).

The remaining student teachers mentioned a variety of factors that are important in assessment but which are related to reliability less directly. For example, 'That all the learners are assessed according to each one's culture and background, without giving advantage to certain learners' (L31) and 'The learner is not placed under pressure. If he did everything right he will be assessed in the proper manner' (L11).

\section{What do you think is meant by the term 'valid assessment'?}

Student teachers who understood the concept of validity in assessment were expected to give an answer similar to: 'Validity is the extent to which an assessment task actually measures what it was designed to measure' (Brady and Kennedy 2001, 3) but it is also important to consider the 'validity of the inferences we make based on the test's results' (Popham 1990, 55). Approximately 29 per cent of respondents indicated a basic understanding of this concept by giving answers such as: 'The extent to which the assessment is assessing the factors that have to be assessed' (L31); 'You must assess what you have taught' (L38); and, 'Assesses what it sets out to assess' (L42 and L46).

A further 13 per cent of respondents related validity to assessment criteria or to assessment of outcomes, with statements such as: 'To assess in a valid way is to list all the applicable criteria of a task and then assess accordingly' (L21) and 'It is assessed according to the outcomes' (L2).

About 13 per cent of the respondents linked validity to fairness. They gave responses such as: 'The assessment must be valid so that it is fair' (L9); 'Did the learners understand what was expected of them and was the assessment fair; was it after the task?' (L15) and 'No injustices are involved here' (L48).

About 21 per cent of respondents saw validity as synonymous with relevance, giving answers such as 'The learner is not assessed on irrelevant things but on things that matter' (L11); 'This is assessing the content etc. that needs to be assessed. Assessing of relevant content' (L28); 'If the results are compared and judged with a similar assessment of the same task it will yield the same results' (L16); and 'The assessment results must be the 
same even when different people assess' (L22).

\section{What do you think is meant by the term 'fair assessment'?}

Student teachers who understood the concept of fairness in assessment were expected to give an answer similar to: Assessment is fair when it is not biased for or against any particular group of students. Approximately 70 per cent of respondents appeared to understand this general concept and gave answers such as: 'Assessment is fair to all learners if it gives them all a chance to achieve according to their different abilities, it is neither biased to very clever students nor to weaker students, it must consider a wide array of learners' (L2); 'A fair assessment would be one in which all learners have equal opportunity to do well, without cultural or language bias. Also the instructions should be clear and learners must know what the outcomes should be, what is expected of them and why they are being assessed' (L15); 'To assess in a fair way is for example, to take a learner's culture and language into account and then assess accordingly. A learner that can scarcely speak English cannot be expected to be assessed in English' (L21); and 'Everybody is assessed according to the same standards, techniques, nobody has an unfair advantage' (L31). The remaining respondents either gave very vague answers or simply restated the question.

\section{What do you understand by the concept 'portfolio assessment'?}

Student teachers who understood the concept of portfolio assessment were expected to describe the idea that learners would collect samples of work in a portfolio to demonstrate how well they had achieved the course outcomes.

Approximately 54 per cent of respondents gave 'correct' responses that demonstrated varying degrees of understanding of at least some of the elements of portfolio assessment and mentioned 'growth' of learners. For example, 'It is a collection compiled by the learner of his work throughout the year. Its assessment will aim to find out how much the learner has progressed and grown educationally. It gives learners multiple opportunities and various ways to demonstrate their understanding' (L15).

A further 42 per cent of respondents described a portfolio as a collection or compilation of work. For example, 'Everything you do is put together and then assessed' (L38) and 'This is assessment based on the collection of your entire work throughout the year. The work is looked through and the best works picked out and put into a portfolio' (L2).

\section{Conclusions}

The findings reported above suggest a wide variation in the knowledge and beliefs of student teachers in this study. These beliefs and understandings need to be built on, not ignored, since student teachers' 'implicit theories and beliefs about assessment inform their thinking and planning and, consequently, shape their classroom assessment 
practices' (Bliem and Davinroy 1997, 3). The limited knowledge about assessment is not a particular problem because these student teachers were just commencing their study of assessment. However, the process of attempting to change this knowledge may be hampered by the beliefs that some of these student teachers hold. As Nespor (1987) points out, teachers' beliefs constitute structural aspects that are distinctly separate from knowledge systems. Therefore, any attempt to impart knowledge will not fulfil its mission unless specific measures are taken to examine and address this belief base. During this process, student teachers' beliefs should not simply be rejected; the legitimacy of their beliefs must be examined and, where appropriate, acknowledged.

There is strong evidence that teachers' beliefs influence the decisions they make when planning, teaching and assessing (Clark and Peterson 1986; Bennett 1997; Putnam and Borko 2000). In the case of South African teachers, their beliefs about assessment will inevitably provide filters through which they will selectively interpret guidelines such as those in the Revised National Curriculum Statement. To the extent that such guidelines are consistent with teachers' beliefs, they are unlikely to be questioned. However, teachers are unlikely to change their beliefs just because they are told to do things that are incompatible with those beliefs. Rather, it will only be when they have been convinced that they should examine the adequacy of their beliefs that they will be able to critically evaluate the changes they are being asked to make.

Encouraging student teachers to make explicit the beliefs that they bring with them when they enter teacher education programmes is an important step in helping them to question and rethink those beliefs. This is particularly important when, as in this study, their beliefs have been shaped by an education system that is quite different from the one they will enter as teachers. When student teachers hold beliefs that are incompatible with the philosophy of the new practices they are required to use, it is essential to help them confront and debate these differences. Through such debate they can challenge their own beliefs and the legitimacy of the practices they are being asked to implement. This study has suggested that reconciling beliefs with required practice might be easy for some new teachers but difficult for others. Likewise this reconciliation might be easier in respect of some practices than others. For example, the responses indicated that many of the student teachers were aware of the limitations of examinations as an assessment method (item 21), norm-referencing (item 17) and marks/grades (item 14). At least in relation to these things they may be receptive to the types of reform that are being suggested for the implementation of outcomes-based assessment in South Africa.

It will be a considerable challenge for teacher educators to identify the preconceptions about assessment that learners bring to their teacher education programme. However, it will be important to do so if learners are to differentiate their initial ideas about assessment from the ideas they are being asked to accept, to challenge them and to integrate aspects of these new ideas into a new set of beliefs. The present study illustrates the importance of being aware of the preconceptions of student teachers - their minds 
are not blank slates, they have some ideas that are compatible with outcomes-based assessment and some that are not. Their prior beliefs and understandings need to be built on, not ignored.

Teacher practices reflect teachers' beliefs which, in turn, reflect their prior experiences and backgrounds. Beliefs change gradually. Teachers need time to accommodate new information, accept and reject ideas, modify existing belief systems and adopt new beliefs (Pajares 1993). It is evident that in order for student teachers in this study to grow professionally, they must modify many of their prior beliefs about assessment so that they can develop their self-image as 'assessors'.

Student teachers must be expected to mediate their understanding of assessment through the filter of their past experiences. Their interpretations of the new ideas that they encounter in their teacher education programme will be influenced by the fact that assessment, as it occurs in schools, 'is far from a merely technical problem, rather it is deeply social and personal' (Johnston et al 1995:359). If new teachers are to commence their careers with beliefs about assessment that are closely aligned with the principles of OBE and with the ideas under-pinning the Revised National Curriculum Statement, these issues must be addressed explicitly.

The backgrounds of the student teachers in this study are not necessarily typical of student teachers in South Africa, but there was no evidence to suggest that their backgrounds made them any more or less knowledgeable about assessment than other South African student teachers. Regardless of their backgrounds, the acquisition of knowledge by itself is unlikely to change beliefs; beliefs change as a result of experience (Pajares 1992). So, while this study has highlighted the need to acknowledge and build on the existing belief systems of student teachers, the bigger challenge of how best to achieve this goal is yet to be addressed.

\section{References}

Anderson, L. and D. Krathwohl. 2001. A taxonomy for learning, teaching and assessing: A revision of Bloom's taxonomy of educational objectives. New York: Longman.

Bennett, C. I. 1997. How can teacher perspectives affect teacher decision making? In Research on the education of our nations' teachers: Teacher education year book, ed. D. M. Byrd and D. J. McIntyre, 75-91. Thousand Oaks, CA: Corwin.

Bliem, C. and K. Davinroy. 1997. Teachers' beliefs about assessment and instruction in literacy. CSE Technical Report 421. Center for the Study of Evaluation, National Centre for Research on Evaluation, Standards and Student Testing, Harvard Graduate School of Education.

Board of Studies New South Wales. 2002. Standards-referenced assessment in primary schools. http://www.bosnsw-k6.nsw.edu.au/parents/k6standards_assess.html (accessed 6 July 2003). 
Brookhart, S. M. and D. J. Freeman. 1992. Characteristics of entering teacher candidates. Review of Educational Research, 62: 37-60.

Clark, C. M. and P. L. Peterson. 1986. Teachers' thought processes. In Handbook of research on teaching, ed. M. C. Wittrock, 255-296. New York: Macmillan.

Delandshere, G. 1999. Elementary teachers' beliefs about assessment in Mathematics: A case of assessment paralysis. Journal of Curriculum and Supervision 14 (3): 215-240.

Department of Education. 2002a. Draf qualifications and assessement policy framework Grades 10-12 (schools). Pretoria: Department of Education.

2002b. Revised National Curriculum Statement for Grades R-9 (Schools). Pretoria:

Department of Education.

.2000. Report of the Review Committee: Executive summary 31 May. Pretoria: Department of Education.

Department of Education and Training. 2003. Quality teaching in NSW public schools: Discussion document. Sydney: NSW Department of Education and Training.

Fleisch, B. D. 2002. Managing educational change: The state and school reform in South Africa. Johannesburg: Heinemann.

Fraser, W. J. and K. Maree, eds. (in press) Outcomes-based assessment. Rondebosch: Heinemann Higher and Further Education.

Gauteng Institute for Curriculum Development. 2000. Formative evaluation of Curriculum 2005 implementation in Gauteng: Year 3 Cycle 3. Johannesburg: Gauteng Institute for Curriculum Development.

Herman, J. L., P. R. Aschbacher and L. Winters. 1992. A practical guide to alternative assessment. Alexandria, VA: Association for Supervision and Curriculum Development.

Hunsaker, L. and M. Johnston. 1992. Teacher under construction: A collaborative case study of teacher change. American Educational Research Journal 29 (2): 350-372.

Jansen, J. D. 2001. Image-ing teachers: Policy images and teacher identity in South African classrooms. South African Journal of Education 21 (4): 242-246.

1999. Why outcomes-based education will fail: An elaboration. In Changing curriculum: Studies on outcomes-based education in South Africa, ed. J. Jansen and P. Christie. South Africa: Kenwyn, Juta and Co.

Jita, L. 2002. Teacher's identities and science teaching: A South African case study. Paper presented at the Comparative International Education Society Conference in Florida.

Johnston, P., S. Guice, K. Baker, J. Malone, and N. Michelson. 1995. Assessment of teaching and learning in literature-based classrooms. Teaching and Teacher Education 11:359-371. 
Killen, R. 2000. Standards-referenced assessment: Linking outcomes, assessment and reporting. Keynote address at the Annual Conference of the Association for the Study of Evaluation in Education in Southern Africa, Port Elizabeth, South Africa, 26-29 September.

_. 2002. Outcomes-based education: Principles and possibilities. Interpretations, 35 (1): 1-18.

_. 2004. Writing outcomes, performance indicators and assessment criteria. In Outcomes-based assessment, ed. W. J. Fraser, and K. Maree. Rondebosch: Heinemann Higher and Further Education.

Kraak, A. and M. Young, ed. 2001. Education in retrospect: Policy and implementation since 1990. Pretoria: Human Sciences Research Council in association with the University of London: Institute of Education.

Luke, A., B. Lingard, J. Ladwig, M. Mills, D. Hayes, and J. Gore. 1998. School reform longitudinal study: Interim report. Submitted to Education Queensland by the Graduate School of Education, The University of Queensland. Brisbane, Australia: University of Queensland.

Malcolm, C. 2000. Implementation of outcomes-based approaches to education in Australia and South Africa: A comparative study. Paper commissioned by the Gauteng Institute for Curriculum Development.

Meier, C. and E. Lemmer. 2001. Future teacher's conceptions concerning the learning capacity of pupils in multicultural schools in South Africa. International Bureau of Education. Prospects 119.

Mkhabela, T. L. 1999. An investigation into Foundation Phase educators' attitudes and classroom practice in relation to Curriculum 2005. MA research report, University of the Witwatersrand.

Nespor, J. 1987. The role of beliefs in the practice of teaching. Journal of Curriculum Studies 19:317-328.

Newmann, F. and Associates. 1996. Authentic achievement: Restructuring schools for intellectual quality. San Francisco: Jossey-Bass.

Pajares, M. F. 1992. Teachers' beliefs and educational research: Cleaning up a messy construct. Review of Educational Research 62 (3): 307-332.

Popham, W. J. 1990. Modern educational measurement. Englewood Cliffs, NJ: Prentice Hall.

Potenza, E. and M. Monyokolo. 1999. A destination without a map: Premature implementation of Curriculum 2005. In Changing curriculum: Studies on outcomes-based education in South Africa, ed. J. Jansen and P. Christie. Kenwyn: Juta and Co.

Putnam, R. T. and H. Borko. 2000. What do new views of knowledge and thinking have to say about research on teacher learning? Educational Researcher 29 (1): 4-15. 
Resnick, L. B. and D. P. Resnick. 1992. Assessing the thinking curriculum: New tools for educational reform. In Future assessments: Changing views of aptitude, achievement, and instruction, ed. B. R. Gifford and M. C. O'Connor. Boston: Kluwer Academic Publishers.

Richards, C. and R. Killen. 1996. Pre-service music teachers: Influences on lesson planning. British Journal of Music Education 13 (1): 40-51.

Rueda, R. and E. Garcia. 1994. Teachers' beliefs about reading assessment with latino language minority students. Research Report 9. National Center for Research on Cultural Diversity and Second Language Learning at the University of California at Santa Cruz.

Rusin, B. 1999. Aligning assessment methods with relevant learning and achievement targets. Paper presented at the IES Classroom Assessment Conference, Sydney.

Spady, W. G. 1994. Outcome-based education: Critical issues and answers. Arlington, VA: American Association of School Administrators.

Tognolini, J. 2000. A standards referenced approach to assessment for the new HSC. http://www. curriculumsupport.nsw.edu.au/hsie/Folder3/jtpaper2.pdf (accessed 6 July 2003).

Vandeyar, S. and R. Killen. 2003. Has curriculum reform in South Africa really changed assessment practices, and what promise does the revised National Curriculum Statement hold? Perspectives in Education 21 (1): 119-134.

Wiggins, G. 1993. Assessment: Authenticity, context, and validity. Phi Delta Kappa, November: 200-213. 
Table 1: Results from questionnaire on OBE Items related to Clarity of Focus

Mean SD

8 Assessment results should be reported in the way that best serves the audience - whoever that may be.

$3.60 \quad 0.76$

14 Marks and letter grades are meaningful ways to report learner achievement

$3.32 \quad 0.89$

18 Learning outcomes should be assessed in real-world contexts.

$4.06 \quad 0.86$

22 Assessment should be used to enhance learning

$4.08 \quad 0.54$

24 Assessment should measure what is valued in student learning.

$3.85 \quad 0.71$

32 The emphasis for reporting assessment results should be on identifying and reporting educational progress and growth, rather than comparing the results of individual learners.

\section{Items related to High Expectations for Learner Success}

7 Effective assessment tasks can involve significant intellectual challenge without dooming large numbers of learners to failure.

$4.00 \quad 0.55$

$4.33 \quad 0.52$

15 Assessment tasks should challenge learners.

$3.31 \quad 1.03$ the standards reached by different learners.

$4.02+0.79$
performance on each assessment task will be judged.

$4.02 \quad 0.79$

Items related to Expanded Learning Opportunities

1 Assessment tasks should be designed so that most learners in a class do well on most tasks.

5 Assessment should promote learning, not just measure it.

6 Assessment should help learners become more self-reflective about their learning.

9 Learners should have multiple opportunities to demonstrate their achievement of each outcome.

$4.00 \quad 0.80$

13 Feedback to learners should always be encouraging and corrective.

$4.02 \quad 0.70$

16 Assessment methods should acknowledge that learners have different learning styles.

$4.19 \quad 0.82$

20 A combination of different assessment methods is vital if teachers are to get a balanced picture of learner achievement.

$4.17 \quad 0.63$

25 Assessment methods should allow learners to demonstrate their understanding in a variety of ways.

$4.19 \quad 0.61$

28 Assessment tasks must respect the cultural and linguistic backgrounds of learners.

$4.19 \quad 0.64$

29 Assessments should be designed to provide learners with multiple opportunities to improve the quality of their work before it becomes 'final'.

30 Assessment should include opportunities for learners to monitor their learning through self-assessment. 
11 Assessment should be integrated as a regular part of each lesson.

12 The primary purpose of assessment is to provide information to the learners and the teacher, which can be used to determine the future direction of the curriculum.

Items related to aligning outcomes, teaching and assessment

2 No one method of assessment can give information about achievement of the full range of learning outcomes in a course.

3 Instructional goals must be considered carefully before meaningful assessments can be designed.

4 Assessment should help teachers focus their instruction more effectively. $4.00 \quad 0.58$

10 The main purpose of assessment is to help improve student-learning outcomes.

19 The main purpose of assessment is to check learners' understanding. $\quad \begin{array}{lll}4.13 & 0.64\end{array}$

21 Written tests and examinations are usually the best way to assess learners' understanding.

$2.44 \quad 0.87$

23 Assessment should always be aligned to learning outcomes.

$4.10 \quad 0.56$

26 All aspects of the assessment process should be open to review and scrutiny.

31 Assessment is most effective when it yields frequent, on-going feedback. 